\title{
Neuroendocrine differentiation in pure type mammary mucinous carcinoma is associated with favorable histologic and immunohistochemical parameters
}

\author{
Gary MK Tse ${ }^{1}$, Tony KF Ma², Winnie CW Chu ${ }^{3}$, Wynnie WM Lam³ ${ }^{3}$ Cycles SP Poon ${ }^{4}$ and \\ Wing-Cheong Chan ${ }^{5}$ \\ ${ }^{1}$ Department of Anatomical and Cellular Pathology, Prince of Wales Hospital, Chinese University of Hong \\ Kong, Hong Kong; ${ }^{2}$ Department of Pathology, Alice Ho Miu Ling Nethersole Hospital, Hong Kong; \\ ${ }^{3}$ Department of diagnostic Radiology and Organ Imaging, Prince of Wales Hospital, Chinese University of \\ Hong Kong, Hong Kong; ${ }^{4}$ Department of Pathology, Northern District Hospital, Hong Kong and ${ }^{5}$ Department \\ of Surgery, Prince of Wales Hospital, Chinese University of Hong Kong, Hong Kong
}

\begin{abstract}
Mucinous carcinoma of the breast is a specific good prognostic type malignancy occurring in elderly patients. Neuroendocrine differentiation has long been described in mucinous carcinoma, but the significance of such finding is uncertain. We evaluated the neuroendocrine differentiation profiles of 38 cases of pure mucinous carcinoma and compared the clinicopathological differences between those with and those without neuroendocrine differentiation. The parameters assessed included patients' age, tumor size, nuclear grade, axillary lymph node status at time of diagnosis, percentage area of intratumoral mucin, and the expression of estrogen and progesterone receptors, cerbB2 oncoprotein, and three neuroendocrine markers, namely neurone-specific enolase, chromogranin, and synaptophysin by immunohistochemistry. Patients' outcome and follow-up period were also documented. Of the 38 cases of pure mucinous carcinoma, 28, 11 and six cases showed positive staining for 1,2 and 3 of the neuroendocrine markers. For all the groups with variable neuroendocrine differentiation and compared to those without such differentiation, they all showed older patients' age, higher proportion of tumors with lower nuclear grade, lower incidence of axillary lymph node metastasis, a higher progesterone receptor, and lower cerbB2 oncoprotein expression. No difference was detected between tumor size, intratumoral mucinous area, and estrogen receptor status. In all, 37 patients did not have distant metastases or local recurrences at the end of follow-up period, while one patient with coexisting high-grade ductal carcinoma in situ at time of diagnosis died of breast carcinoma. Our findings suggest that the identification of neuroendocrine differentiation in pure mucinous carcinoma is associated with more favorable histologic and immunohistochemical parameters.
\end{abstract}

Modern Pathology (2004) 17, 568-572, advance online publication, 5 March 2004; doi:10.1038/modpathol.3800092

Keywords: breast; mucinous carcinoma; neuroendocrine

Mucinous carcinoma of the breast is a well-recognized specific type of carcinoma with good prognosis. The clinicopathological features have been well described, as small clusters of tumor cells, usually of low to intermediate grade, with abundant extracellular mucin accumulation. ${ }^{1-3}$ The patients tend to be elderly, and lymph node metastasis is

Correspondence: Gary MK Tse, Senior Medical Office, Department of Anatomical and Cellular Pathology, Prince of Wales Hospital, Ngan Shing Hospital, Shatin, NT, Hong Kong.

E-mail: garytse@cuhk.edu.hk

Received 13 August 2003; revised 20 November 2003; accepted 24 November 2003; published online 5 March 2004 uncommon. Mucinous carcinoma has been grouped into pure and mixed types, with the former containing only tumor with the typical mucinous carcinoma morphology, and the latter mixed with conventional infiltrating ductal carcinoma. The good prognostic implication only applies to the former group. Neuroendocrine differentiation in mucinous carcinoma has long been observed, either by immunohistochemistry or electron microscopy. ${ }^{4-7}$ The significance of neuroendocrine differentiation in mucinous carcinoma has been controversial, with some authors reporting a difference in patients' age and prognosis, ${ }^{4,6}$ while other authors concluded that no difference existed. ${ }^{5,7,8}$ In this study, we further 
evaluated the clinicopathological differences between pure mucinous carcinoma with or without neuroendocrine differentiation.

\section{Materials and methods}

The histopathology files of the two hospitals (PWH, AHMLNH) were searched for mucinous carcinoma, and all the slides were retrieved and reviewed. All the cases were either excisions or needle-core biopsies, and the specimens had been fixed in buffered formalin, and routinely processed and stained with H\&E. During histological review the tumors were assessed for the presence of nonmucinous invasive carcinoma (mixed type), and these cases were excluded from this study. For the remaining pure mucinous carcinoma, the following parameters were assessed: tumor size, nuclear grade (low (1), moderate (2) or high (3)), the lymph node status and the percentage area of intratumoral mucin. Immunohistochemistry was performed on a representative block for estrogen receptor (Novacastra, UK, 1:40), progesterone receptor (Novacastra, UK, 1:40), cerbB2 oncoprotein (Dako, Denmark, 1:500), neurone-specific enolase (Dako, Denmark, 1:250), chromogranin (Biogenix, CA, USA, 1:600), and synaptophysin (Novacastra, UK, 1:150). For estrogen and progesterone receptors, the percentage of cells showing moderate to strong nuclear staining were assessed, for cerbB2, moderate to strong complete membrane staining for more than $10 \%$ cells was considered positive, and for neurone-specific enolase, chromogranin and synaptophysin, granular cytoplasmic staining of more than $20 \%$ cells was considered positive.

The individual patients age, follow-up duration and outcome (dead or alive, presence or absence of local recurrence or metastases) were also documented.

The difference between patient's age, tumor size, nuclear grade, lymph node status, intratumoral mucin, estrogen and progesterone receptors status, and cerbB2 expression between tumors with or without expression of each or combinations of the three neuroendocrine differentiation markers were compared using Student's $t$-test. Statistical significance is established at $P<0.05$.

\section{Results}

A total of 40 cases of mucinous carcinoma were retrieved, with two cases of mixed-type histology, and were thus excluded from this study. The 38 pure mucinous carcinomas were derived from 34 patients, with three patients having bilateral tumors and one patient having two discrete tumors in the same breast. All the four pairs of double tumors were synchronous. Of these, 27 tumors showed mucinous carcinoma only, and 11 showed coexisting ductal carcinoma in situ. The patients' age range was 35-101 years (mean 66 years) and the tumor size range was $0.4-11 \mathrm{~cm}$ (mean $3.7 \mathrm{~cm}$ ). Mastectomies were performed in 36 cases, and biopsies in two. A total of 20 tumors were on the left side and 16 were on the right side. Axillary dissections were performed in 30 tumors, and it was not conducted in eight tumors because of coexisting medical conditions, or because of the absence of evidence of metastasis (normal imaging with or without negative fine-needle aspiration cytology).

Among all cases, low-nuclear grade occurred in 26 cases (68\%), and intermediate grade nuclei occurred in 12 cases (32\%) (Figure 1). In 24 cases the axillary lymph nodes were negative, together with the eight cases without clinical or radiological evidence of metastasis, this group accounted for $82 \%$ of cases, while positive axillary nodes occurred in seven cases $(18 \%)$, with the number of positive nodes ranging from 1-13 (mean 2.9 nodes). Estrogen receptor showed some staining in 36 cases $(95 \%)$, ranging from 10 to $100 \%$, (mean $82 \%$ ); progesterone receptor showed some staining in 32 cases $(84 \%)$, ranging from 10 to $100 \%$, (mean 60\%). Each tumor was assessed as to the expression of each of the three neuroendocrine markers, and combinations of any one out of three, two out of the three, and all three (Figure 2). The results are tabulated in Table 1.

Of the 34 patients, six were lost to follow-up, and for the remaining 28 patients, the follow-up period ranged from 0 to 96 months (mean 28 months). All but two patients were put on Tamoxifen, and in addition, four patients had additional chemotherapy, two had local radiotherapy, and four had both chemotherapy and local radiotherapy. Of these 28 patients, one patient died of the disease after 36 months with local recurrence and distant metastasis. She had a coexisting high-grade ductal carcinoma in situ with 13 metastatic axillary nodes at the

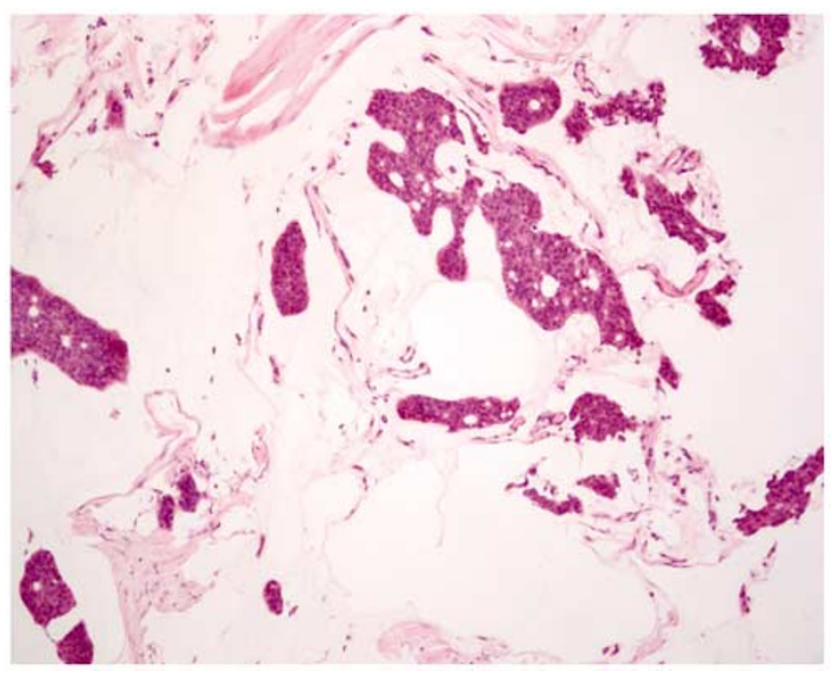

Figure 1 Photomicrograph of mucinous carcinoma, with the typical histomorphology of clusters of rather bland-looking tumor cells floating within a sea of mucin. 
570

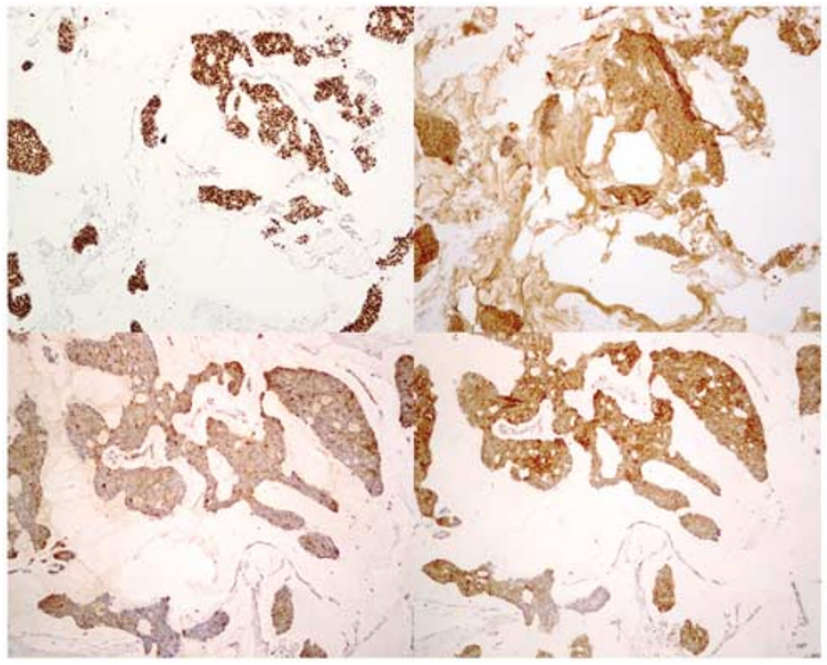

Figure 2 Immunohistochemistry of the same tumor showing positivity for estrogen receptor (ER, upper left panel), progesterone receptor (PR, upper right panel), chromogranin (lower left panel) and synaptophysin (lower right panel).

time of diagnosis. Two other patients died of unrelated causes at the age of 87 and 79 years. These two patients, together with all 25 surviving patients, did not have any local recurrences or distant metastases at the end of the follow-up period.

Of all the 38 tumors, 24 (63\%), $10(26 \%)$ and 10 $(26 \%)$ tumors were positive for neurone specific enolase, chromogranin, and synaptophysin. Viewed from another angle, 28 (74\%), 11 (29\%) and six $(16 \%)$ tumors showed positivity for any one of the three, two of the three and all three markers. For all the groupings, the mean patient age was higher in those with neuroendocrine differentiation than those without, and statistical significance was established for the groups with neurone specific enolase positivity (71 vs 58 years), and the group with two of three markers positive (77 vs 62 years). For the tumor nuclear grade, all but one groups with neuroendocrine differentiation showed higher proportion of lower nuclear grade than those without, with the group with two out of three markers positive reaching statistical significance (91 vs $59 \%$ showing low-nuclear grade). For the lymph node status, all groups with neuroendocrine differentiation showed higher proportion of cases without lymph node metastasis, and statistical significance was established for the group with neurone specific enolase positivity ( 96 vs $64 \%$ negative axilla). There was no difference between the tumor sizes and the intratumoral mucinous areas when comparing all the groups with neuroendocrine differentiation than those without.

For the estrogen receptor, there was no difference between those groups with or without variable neuroendocrine differentiation, even though both groups showed high expression, as in the entire series, only two cases did not show any estrogen receptor staining. For the progesterone receptor, there was a higher expression in all the groups with neuroendocrine differentiation, reaching statistical significance for the group expressing chromogranin (73 vs $43 \%$ expression of progesterone receptor). For cerbB2 oncoprotein, there was lower expression in all the groups with neuroendocrine differentiation than those without, reaching statistically significance in the group staining positive for neurone specific enolase (0 vs $21 \%$ positive for cerbB2).

\section{Discussion}

Neuroendocrine differentiation of mucinous carcinoma has been reported since $1980,{ }^{4}$ with the tumor being classified as type A (without neuroendocrine differentiation), type B (with neuroendocrine differentiation) and type $A B$, the intermediate form. The significance of neuroendocrine differentiation in mucinous carcinoma has not been well established. In the original description by Capella et al, ${ }^{4}$ the only difference reported was the older age group of patients with mucinous carcinoma with neuroendocrine differentiation. In the literature, there are a few large series analyzing this phenomenon in mucinous carcinoma, and many authors concluded that there was no difference between mucinous carcinoma with or without neuroendocrine differentiation in terms of predictive value, growth patterns, and estrogen receptor status, ${ }^{5,7}$ while another recent series did not analyze these prognostic parameters. ${ }^{8}$

The expression of neuroendocrine markers is not unique to mucinous carcinoma of the breast. This phenomenon has been described in other breast carcinomas, including ductal carcinoma in situ (termed endocrine ductal carcinoma in situ, ${ }^{9}$ ); the small-cell undifferentiated carcinoma that resembles small-cell carcinoma or Merkel cell carcinoma; infiltrating lobular carcinoma; and low-grade insular ductal carcinoma. ${ }^{10}$ Some of these lesions are low grade, and others are of intermediate to high grade. It thus appears that endocrine differentiation of breast carcinoma can occur in a heterogeneous manner. The so-called 'carcinoid' tumors of the breast, in particular, the mucinous variety ${ }^{11,12}$ may represent significant histologic overlap with pure type mucinous carcinoma with neuroendocrine differentiation, with reportedly favorable prognosis.

The criterion for diagnosing neuroendocrine differentiation in breast carcinomas was variable, although most authors based the diagnosis on immunohistochemistry. Some authors consider expression of chromogranin and synpatrophysin definitive, ${ }^{10}$ and had commented on the 'nonspecific' nature of neurone-specific enolase, ${ }^{10}$ and other authors used two out of three positivity. ${ }^{9}$ In this study, the authors compared all possible combinations, and essentially the results were similar for using positivity of any one of the three 
Table 1 Data of all patients

\begin{tabular}{|c|c|c|c|c|c|c|c|c|c|c|c|c|c|c|c|}
\hline$P$ & $\begin{array}{c}\text { Age } \\
\text { (years) }\end{array}$ & Side & $\begin{array}{l}\text { Size } \\
(\mathrm{cm})\end{array}$ & $L N$ & $\mathrm{Nu}$ & $\begin{array}{c}I M A \\
(\%)\end{array}$ & $\begin{array}{c}E R \\
(\% \text { cell })\end{array}$ & $\begin{array}{c}P R \\
(\% \text { cell) }\end{array}$ & cerbB2 & $N S E$ & $C g$ & $S n$ & $N E-1$ & $N E-2$ & $N E-3$ \\
\hline 1 & 95 & $\mathrm{R}$ & 1.2 & 0 of 35 & 1 & 80 & 80 & 60 & $\mathrm{n}$ & $\mathrm{p}$ & $\mathrm{p}$ & $\mathrm{p}$ & $\mathrm{p}$ & $\mathrm{p}$ & $\mathrm{p}$ \\
\hline 2 & 70 & $\mathrm{~L}$ & 2.5 & 0 of 23 & 1 & 10 & 70 & 25 & $\mathrm{n}$ & $\mathrm{p}$ & $\mathrm{p}$ & $\mathrm{p}$ & $\mathrm{p}$ & $\mathrm{p}$ & $\mathrm{p}$ \\
\hline 3 & 84 & $\mathrm{~L}$ & 4.8 & 0 of 10 & 2 & 20 & 90 & 60 & $\mathrm{n}$ & $\mathrm{p}$ & $\mathrm{n}$ & $\mathrm{p}$ & $\mathrm{p}$ & $\mathrm{p}$ & $\mathrm{n}$ \\
\hline 4 & 78 & $\mathrm{~L}$ & 1.7 & 0 (nd) & 1 & 90 & 50 & 10 & $\mathrm{n}$ & $\mathrm{p}$ & $\mathrm{n}$ & $\mathrm{p}$ & $\mathrm{p}$ & $\mathrm{p}$ & $\mathrm{n}$ \\
\hline 5 & 64 & $\mathrm{R}$ & 1 & 0 of 10 & 1 & 95 & 60 & 30 & $\mathrm{n}$ & $\mathrm{p}$ & $\mathrm{n}$ & $\mathrm{p}$ & $\mathrm{p}$ & $\mathrm{p}$ & $\mathrm{n}$ \\
\hline 6 & 84 & L-med & 6 & 0 of 15 & 1 & 80 & 80 & 90 & $\mathrm{n}$ & $\mathrm{p}$ & $\mathrm{p}$ & $\mathrm{p}$ & $\mathrm{p}$ & $\mathrm{p}$ & $\mathrm{p}$ \\
\hline 7 & 84 & L-lat & 6.5 & 0 of 15 & 1 & 80 & 70 & 80 & $\mathrm{n}$ & $\mathrm{p}$ & $\mathrm{p}$ & $\mathrm{p}$ & $\mathrm{p}$ & $\mathrm{p}$ & $\mathrm{p}$ \\
\hline 8 & 66 & $\mathrm{R}$ & 4 & 0 of 19 & 1 & 50 & 100 & 100 & $\mathrm{n}$ & $\mathrm{p}$ & $\mathrm{p}$ & $\mathrm{n}$ & $\mathrm{p}$ & $\mathrm{p}$ & $\mathrm{n}$ \\
\hline 9 & 79 & $\mathrm{R}$ & 4 & 0 of 25 & 1 & 50 & 95 & 80 & $\mathrm{n}$ & $\mathrm{p}$ & $\mathrm{p}$ & $\mathrm{p}$ & $\mathrm{p}$ & $\mathrm{p}$ & $\mathrm{p}$ \\
\hline 10 & 69 & $\mathrm{~L}$ & 2.5 & 0 of 19 & 1 & 80 & 95 & 80 & $\mathrm{n}$ & $\mathrm{p}$ & $\mathrm{p}$ & $\mathrm{p}$ & $\mathrm{p}$ & $\mathrm{p}$ & $\mathrm{p}$ \\
\hline 11 & 71 & $\mathrm{R}$ & 0.4 & 0 (nd) & 1 & 50 & 100 & 100 & $\mathrm{n}$ & $\mathrm{p}$ & $\mathrm{p}$ & $\mathrm{n}$ & $\mathrm{p}$ & $\mathrm{p}$ & $\mathrm{n}$ \\
\hline 12 & 65 & $\mathrm{~L}$ & 2 & 0 of 8 & 1 & 70 & 80 & 10 & $\mathrm{n}$ & $\mathrm{p}$ & $\mathrm{n}$ & $\mathrm{n}$ & $\mathrm{p}$ & $\mathrm{n}$ & $\mathrm{n}$ \\
\hline 13 & 101 & $\mathrm{~L}$ & 7 & 0 (nd) & 1 & 95 & 80 & 10 & $\mathrm{n}$ & $\mathrm{n}$ & $\mathrm{n}$ & $\mathrm{n}$ & $\mathrm{n}$ & $\mathrm{n}$ & $\mathrm{n}$ \\
\hline 14 & 84 & $\mathrm{~L}$ & 1.5 & 0 (nd) & 1 & 80 & 80 & 90 & $\mathrm{n}$ & $\mathrm{p}$ & $\mathrm{n}$ & $\mathrm{n}$ & $\mathrm{p}$ & $\mathrm{n}$ & $\mathrm{n}$ \\
\hline 15 & 81 & $\mathrm{~L}$ & 3 & 0 (nd) & 1 & 80 & 80 & 0 & $\mathrm{n}$ & $\mathrm{p}$ & $\mathrm{n}$ & $\mathrm{n}$ & $\mathrm{p}$ & $\mathrm{n}$ & $\mathrm{n}$ \\
\hline 16 & 78 & $\mathrm{R}$ & 6 & 0 of 11 & 1 & 90 & 60 & 40 & $\mathrm{p}$ & $\mathrm{p}$ & $\mathrm{n}$ & $\mathrm{n}$ & $\mathrm{p}$ & $\mathrm{n}$ & $\mathrm{n}$ \\
\hline 17 & 50 & $\mathrm{~L}$ & 8 & 4 of 14 & 1 & 95 & 0 & 0 & $\mathrm{n}$ & $\mathrm{n}$ & $\mathrm{n}$ & $\mathrm{n}$ & $\mathrm{n}$ & $\mathrm{n}$ & $\mathrm{n}$ \\
\hline 18 & 43 & $\mathrm{R}$ & 1.5 & 0 of 26 & 2 & 80 & 80 & 20 & $\mathrm{n}$ & $\mathrm{p}$ & $\mathrm{n}$ & $\mathrm{n}$ & $\mathrm{p}$ & $\mathrm{n}$ & $\mathrm{n}$ \\
\hline 19 & 48 & $\mathrm{R}$ & 2.3 & 0 of 37 & 1 & 90 & 80 & 0 & $\mathrm{n}$ & $\mathrm{n}$ & $\mathrm{n}$ & $\mathrm{n}$ & $\mathrm{n}$ & $\mathrm{n}$ & $\mathrm{n}$ \\
\hline 20 & 89 & $\mathrm{~L}$ & na & 0 (nd) & 2 & 50 & 100 & 100 & $\mathrm{n}$ & $\mathrm{n}$ & $\mathrm{n}$ & $\mathrm{n}$ & $\mathrm{n}$ & $\mathrm{n}$ & $\mathrm{n}$ \\
\hline 21 & 42 & $\mathrm{~L}$ & 2.5 & 0 of 12 & 2 & 50 & 80 & 60 & $\mathrm{n}$ & $\mathrm{n}$ & $\mathrm{n}$ & $\mathrm{n}$ & $\mathrm{p}$ & $\mathrm{n}$ & $\mathrm{n}$ \\
\hline 22 & 50 & $\mathrm{R}$ & 4.5 & 0 of 15 & 2 & 70 & 80 & 90 & $\mathrm{n}$ & $\mathrm{p}$ & $\mathrm{n}$ & $\mathrm{n}$ & $\mathrm{p}$ & $\mathrm{n}$ & $\mathrm{n}$ \\
\hline 23 & 72 & $\mathrm{R}$ & 2 & 0 of 1 & 1 & 60 & 100 & 10 & $\mathrm{n}$ & $\mathrm{n}$ & $\mathrm{n}$ & $\mathrm{n}$ & $\mathrm{n}$ & $\mathrm{n}$ & $\mathrm{n}$ \\
\hline 24 & 82 & $\mathrm{R}$ & 0.5 & 0 of 2 & 1 & 60 & 100 & 80 & $\mathrm{n}$ & $\mathrm{n}$ & $\mathrm{n}$ & $\mathrm{n}$ & $\mathrm{n}$ & $\mathrm{n}$ & $\mathrm{n}$ \\
\hline 25 & 35 & $\mathrm{~L}$ & 1.4 & 0 (nd) & 2 & 40 & 80 & 80 & $\mathrm{p}$ & $\mathrm{n}$ & $\mathrm{n}$ & $\mathrm{n}$ & $\mathrm{n}$ & $\mathrm{n}$ & $\mathrm{n}$ \\
\hline 26 & 76 & $\mathrm{R}$ & 4 & 2 of 4 & 1 & 50 & 100 & 20 & $\mathrm{n}$ & $\mathrm{n}$ & $\mathrm{n}$ & $\mathrm{n}$ & $\mathrm{n}$ & $\mathrm{n}$ & $\mathrm{n}$ \\
\hline 27 & 40 & $\mathrm{R}$ & 4.5 & 0 of 15 & 2 & 60 & 100 & 100 & $\mathrm{n}$ & $\mathrm{p}$ & $\mathrm{n}$ & $\mathrm{n}$ & $\mathrm{p}$ & $\mathrm{n}$ & $\mathrm{n}$ \\
\hline 28 & 40 & $\mathrm{~L}$ & 6 & 0 of 12 & 2 & 60 & 100 & 100 & $\mathrm{n}$ & $\mathrm{p}$ & $\mathrm{n}$ & $\mathrm{n}$ & $\mathrm{p}$ & $\mathrm{n}$ & $\mathrm{n}$ \\
\hline 29 & 47 & $\mathrm{~L}$ & 6 & 11 of 20 & 2 & 60 & 70 & 20 & $\mathrm{p}$ & $\mathrm{n}$ & $\mathrm{p}$ & $\mathrm{n}$ & $\mathrm{p}$ & $\mathrm{n}$ & $\mathrm{n}$ \\
\hline 30 & 42 & $\mathrm{~L}$ & 1.5 & 0 of 11 & 1 & 70 & 100 & 100 & $\mathrm{n}$ & $\mathrm{n}$ & $\mathrm{p}$ & $\mathrm{n}$ & $\mathrm{p}$ & $\mathrm{n}$ & $\mathrm{n}$ \\
\hline 31 & 38 & $\mathrm{~L}$ & 11 & 13 of 16 & 2 & 20 & 0 & 0 & $\mathrm{p}$ & $\mathrm{n}$ & $\mathrm{n}$ & $\mathrm{p}$ & $\mathrm{p}$ & $\mathrm{n}$ & $\mathrm{n}$ \\
\hline 32 & 77 & $\mathrm{~L}$ & 2.5 & 0 of 18 & 1 & 85 & 80 & 80 & $\mathrm{n}$ & $\mathrm{p}$ & $\mathrm{n}$ & $\mathrm{n}$ & $\mathrm{p}$ & $\mathrm{n}$ & $\mathrm{n}$ \\
\hline 33 & 79 & $\mathrm{~L}$ & 5.5 & 0 of 27 & 1 & 60 & 70 & 0 & $\mathrm{n}$ & $\mathrm{p}$ & $\mathrm{n}$ & $\mathrm{n}$ & $\mathrm{p}$ & $\mathrm{n}$ & $\mathrm{n}$ \\
\hline 34 & 45 & $\mathrm{~L}$ & 1.2 & 0 (nd) & 1 & 80 & 70 & 40 & $\mathrm{n}$ & $\mathrm{n}$ & $\mathrm{n}$ & $\mathrm{n}$ & $\mathrm{n}$ & $\mathrm{n}$ & $\mathrm{n}$ \\
\hline 35 & 68 & $\mathrm{~L}$ & 2 & 0 of 19 & 1 & 90 & 95 & 15 & $\mathrm{n}$ & $\mathrm{p}$ & $\mathrm{n}$ & $\mathrm{n}$ & $\mathrm{p}$ & $\mathrm{n}$ & $\mathrm{n}$ \\
\hline 36 & 77 & $\mathrm{R}$ & 1.7 & 0 of 14 & 2 & 85 & 80 & 70 & $\mathrm{n}$ & $\mathrm{p}$ & $\mathrm{n}$ & $\mathrm{n}$ & $\mathrm{p}$ & $\mathrm{n}$ & $\mathrm{n}$ \\
\hline 37 & 74 & $\mathrm{R}$ & 2.8 & 1 of 17 & 1 & 70 & 90 & 80 & $\mathrm{n}$ & $\mathrm{p}$ & $\mathrm{n}$ & $\mathrm{n}$ & $\mathrm{p}$ & $\mathrm{n}$ & $\mathrm{n}$ \\
\hline 38 & 43 & $\mathrm{R}$ & 10 & 7 of 13 & 2 & 95 & 10 & 0 & $\mathrm{n}$ & $\mathrm{n}$ & $\mathrm{n}$ & $\mathrm{n}$ & $\mathrm{n}$ & $\mathrm{n}$ & $\mathrm{n}$ \\
\hline
\end{tabular}

R: right; L: left; med: medial, lat: lateral; na: not available; LN: lymph node status positive for metastases; nd: not done; Nu: nuclear grade; IMA: intratumoral mucinous area; ER: estrogen receptor; PR: progesterone receptor; p: positive; n: negative; NSE: neurone-specific enolase; Cg: chromogranin; Sn: synaptophysin; NE-1: 1 of 3 neuroendocrine markers positive; NE-2: 2 of 3 neuroendocrine markers positive; NE-3: all 3 neuroendocrine markers positive.

neuroendocrine markers or any combinations of one, two or three out of the three markers as the diagnostic criteria. It is likely that with a larger series, statistical significance may be established in more of the relationships analyzed.

The evaluation of outcome of pure mucinous carcinoma is particularly difficult, as many patients are elderly, and as the tumor is of low grade, many patients may die of other unrelated causes. Any attempt to assess the outcome of mucinous carcinoma with or without neuroendocrine differentiation is by necessity hampered by the age of the patients. As evidenced in the current series, which is limited by the small number of patients involved and the relatively short follow-up period, the majority of the patients did not have any local regional recurrences or distant metastases, and of the three patients who died, two were due to unrelated causes. Hence, a more feasible way may be to assess the tumor nuclear grade and lymph node metastases, as these represent independent prognostic indicators.

In the current series, we found a difference in patients' age, with patients having mucinous carcinoma with neuroendocrine differentiation being older. For other morphologic parameters with prognostic implications, mucinous carcinoma with neuroendocrine differentiation showed higher proportion of lower tumor nuclear grade and lower incidence of lymph node metastases. Furthermore, this group showed higher expression of progesterone receptor and lower cerbB2 oncoprotein expression, but not for estrogen receptor. The increased proportion of tumor expressing progesterone receptor is of particular interest, as in a study on breast cancers in elderly patients over the age of 85 years, ${ }^{13}$ there was actually significantly less proportion of tumor expressing progesterone receptor in this group of elderly patients. Hence, the observed 
increased progesterone receptor expression in the mucinous carcinoma with neuroendocrine differentiation may not be explained by the age difference alone. The underlying mechanism for this phenomenon remains elusive.

In this study, we demonstrated that a significant portion of pure mucinous carcinoma, known for having good prognosis, showed neuroendocrine differentiation. This subgroup was characterized by older patient age, and was associated with more favorable histologic and immunohistochemical parameters including lower tumor nuclear grade, lower incidence of axillary lymph node metastasis, and lower cerbB2 oncoprotein expression.

\section{References}

1 Page DL, Sakamoto G. Infiltrating carcinoma: major histological types. In: Page DL, Anderson TJ (eds). Diagnostic Histopathology of the Breast. Churchill Livingstone; Edinburgh, 1987, pp 206-210.

2 Pinder SE, Elston CW, Ellis IO. Invasive carcinomausual histological types. In: Elston CW, Ellis IO (eds). Systemic Pathology, Vol. 13, 3rd edn. Churchill Livingstone; Edinburgh, 1998, pp 315-319.

3 Rosen PP. Mucinous carcinoma. In: Rosen's Breast Pathology, 2nd edn. Lippincott Williams \& Wilkins; Philadelphia, PA, 2001, pp 463-481.

4 Capella C, Eusebi V, Mann B, et al. Endocrine differentiation in mucoid carcinoma of the breast. Histopathology 1980;4:613-630.
5 Rasmussen BB, Rose C, Thorpe SM, et al. Argyrophilic cells in 202 human mucinous breast carcinomas. Am J Clin Pathol 1985;84:737-740.

6 Coady AT, Shousha S, Dawson PM, et al. Mucinous carcinoma of the breast: further characterization of its three subtypes. Histopathology 1989;15:617-626.

7 Scopi L, Andreola S, Pilotti S, et al. Mucinous carcinoma of the breast. A clinicopathologic, histochemical and immunocytochemical study with special reference to neuroendocrine differentiation. Am J Surg Pathol 994;18:702-711.

8 Kato N, Endo Y, Tamura G, et al. Mucinous carcinoma of the breast: a multifaceted study with special reference to histogenesis and neuroendocrine differentiation. Pathol Int 1999;49:947-955.

9 Tsang WY, Chan JK. Endocrine ductal carcinoma in situ (E-DCIS) of the breast: form of low grade DCIS with distinctive clinicopathologic and biologic characteristics. Am J Surg Pathol 1996;20:921-943.

10 Maluf HM, Koerner FC. Carcinomas of the breast with endocrine differentiation: a review. Virchows Arch 1994;425:449-457.

11 Azzopardi JG, Muretto P, Goddeeris P, et al. 'Carcinoid' tumours of the breast: the morphological spectrum of argyrophil carcinomas. Histopathology 1982;6: 549-569.

12 Fisher ER, Palekar A. Solid and mucinous varieties of so-called mammary carcinoid tumors. Am J Clin Pathol 1979;72:909-916.

13 Honma N, Sakamoto G, Akiyama F, et al. Breast carcinoma in women over the age of 85: distinct histological pattern and androgen, oestrogen, and progesterone receptor status. Histopathology 2003;42: $120-127$. 